\title{
Formação continuada: um mapeamento dos programas oferecidos aos professores dos anos iniciais do ensino fundamental
}

\author{
Roberta Miranda Silva \\ Universidade Federal de Uberlândia - UFU, Brasil \\ Maria Célia Borges \\ Universidade Federal de Uberlândia - UFU, Brasil \\ Universidade Federal do Triângulo Mineiro - UFTM, Brasil
}

\begin{abstract}
RESUMO
O artigo, recorte da dissertação de mestrado na UFU, propõe expor sobre as principais políticas educacionais de formação continuada oferecidas aos docentes dos anos iniciais do Ensino Fundamental no Brasil desde o início do século XXI. Tem como objetivo descrever as propostas dos principais programas de formação continuada implantados pelo Governo Federal a partir do ano de 2002, buscando compreender os resultados que elas refletem e no que contribuem para o perfil docente. A proposta é mapear os objetivos desses programas e suas ações para a formação continuada desses professores, além de ressaltar a busca contínua pelo desenvolvimento do ensino público no País. É importante destacar também o valor das ações políticas que contribuem para o desenvolvimento e a formação do professor, além de priorizar a capacitação docente.
\end{abstract}

PALAVRAS-CHAVE: formação continuada; políticas públicas; programas de governo.

\section{CONTINUING EDUCATION: A MAPPING OF THE PROGRAMS OFFERED TO TEACHERS IN THE INITIAL YEARS OF ELEMENTARY EDUCATION}

\begin{abstract}
The article, cut of the dissertation of Master in UFU, proposes to present on the main educational policies of continuing education developed to the teachers of the initial years of elementary education in Brazil since the beginning of the 21st century. It aims to describe the proposals of the main continuing education programs implemented by the Federal Government from 2002 onwards, seeking to understand the results they reflect and in what contribute to the teaching profile. The proposal is to map the objectives of these programs and their actions towards the continued education of these teachers, in addition to highlighting the continuous search for the development of public education in the country. It is also important to highlight the value of political actions that contribute to the development and training of teachers, in addition to prioritizing teacher training.
\end{abstract}

KEYWORDS: continuing education; public policy; government programs. 


\title{
FORMACIÓN CONTINUADA: UN MAPEO DE LOS PROGRAMAS OFRECIDOS A LOS PROFESORES DE LOS AÑOS INICIALES DE LA ENSEÑANZA FUNDAMENTAL
}

\begin{abstract}
RESUMEN
El artículo, recorte de la disertación de Maestría en la UFU, propone exponer sobre las principales políticas educativas de formación continuada desarrolladas a los docentes de los años iniciales de la enseñanza fundamental en Brasil desde el inicio del siglo XXI. Tiene como objetivo describir sobre las propuestas de los principales programas de formación continuada implantados por el gobierno federal a partir del año 2002, buscando comprender los resultados que reflejan y contribuyen en el perfil docente. La propuesta es mapear, los objetivos de esos programas y sus acciones para con la formación continuada de esos profesores, además de resaltar la búsqueda continua por el desarrollo de la enseñanza pública en el país. Es importante destacar también la importancia de las acciones políticas que contribuyen al desarrollo y la formación del profesor, además de priorizar la capacitación docente.
\end{abstract}

PALABRAS CLAVE: formación continuada; políticas públicas; programas de gobierno.

\section{INTRODUÇÃO}

Muitos são os temas que contemplam as discussões sobre a Educação. A formação de professores é uma área que recebe muita atenção, pois se considera muito importante a participação do docente no processo de ensino-aprendizagem. Sua qualificação é de grande influência nas questões políticas, econômicas e sociais do País. O desenvolvimento profissional do professor é um fator de interferência nas práticas ensino, no rendimento dos estudantes e em suas próprias atitudes.

Na concepção de que o professor necessita estar sempre atualizado e amparado pelo conhecimento contínuo, o foco do artigo é voltado à formação continuada. As ações docentes desenvolvidas no dia a dia apresentam, mesmo que indiretamente, a necessidade de se manter constantemente em formação para que se possa desenvolver o conhecimento e aprender novas concepções e didática a serem aplicadas em sua atuação. Alvarado-Prada (2010) contempla com a afirmação de que é necessário realizar processos formativos considerando a trajetória do docente, pois ela traz consigo as contradições da relação teoria-prática. Por meio dessa concepção, é que o texto busca responder à seguinte questão: como as propostas de formação continuada oferecidas pelas políticas públicas nacionais do século XXI são aplicadas aos docentes em exercício e quais são elas?

É importante ressaltar que o texto não busca apresentar resultados definitivos e conclusos sem a possibilidade de novas pesquisas, mas sim contribuir com o tema e com novas 
investigações científicas. $\mathrm{O}$ artigo tem como objetivo identificar as contribuições das propostas de formação continuada oferecidas pelas políticas públicas nacionais do século XXI ao perfil e aos saberes dos docentes dos anos iniciais do Ensino Fundamental. Usa, como metodologia, a descrição de propostas por meio de pesquisas bibliográficas e documentais. A descrição de todo o processo de pesquisa e a análise da extensão dos programas de formação continuada ofertados pelas políticas educacionais visam explorar sua contribuição no currículo, na qualificação e na prática docente dos professores neles envolvidos. Dentro dessa análise, o tex to procura abranger os subsídios desses programas, a evolução do conhecimento pedagógico e a complementação que propõem ao perfil dos professores cursistas dessas propostas de formação continuada.

Dessa forma, o texto delineia propostas de formação continuada estabelecidas pelas políticas educacionais aos professores de anos inicias do Ensino Fundamental no século XXI. Neste artigo, a discussão está voltada à diversidade de perspectivas nacionais de formação de professores a partir de alguns programas de formação continuada.

É nesse contexto que o artigo, - que é um recorte da dissertação de mestrado apresentada em agosto de 2017, intitulada "Formação continuada de professores: propostas e contribuições para os anos iniciais do Ensino Fundamental no início do século XXI”, apresentada na linha de pesquisa Estado, Políticas e Gestão da Educação, do programa de pós-graduação em Educação da Universidade Federal de Uberlândia -, faz uma descrição e um mapeamento dos programas de formação contínua para o enriquecimento do conhecimento e da qualificação docente. Gatti (2012) descreve sobre essas propostas e conceitua que,

[...] assistimos à emergência de propostas e de implementação de ações interventivas relativas a essa formação que têm grande abrangência embora não cheguem a reestruturações mais profundas nessa formação e nos conteúdos formativos. Porém, mobilizam na direção de uma atenção maior aos cursos de licenciatura e a aspectos específicos de formação inicial. Vários programas foram elaborados e postos em prática nos últimos anos pelo governo federal visando os cursos formadores de professores. Algumas ações implementadas em relação ao ensino superior, como um todo, também tiveram seus reflexos sobre os cursos de licenciatura (GATTI, 2012, p. 7-8)

Para a autora, há uma carência visível de políticas de ação que se voltem para essa qualificação profissional, em nível estrutural e efeito. Destarte, a reflexão das propostas de formação continuada ofertadas pelas políticas educacionais, descritas nessa parte do texto, estão explicitadas em suas características, propostas, abrangência, vivência, objetivos de formação e extensão, entre outros conceitos.

A participação do Governo em contribuição ao processo formativo desses professores também está pautada na desenvoltura de reconhecer e identificar sua dedicação e consideração 
para com os saberes docentes. Para Pimenta (2005), no que se refere à formação contínua, a prática mais frequente tem sido a de realizar cursos de suplência e/ou atualização dos conteúdos.

Dessa forma, entende-se que os programas de formação continuada devem ser articuladores tendo como eixo a reflexão crítica sobre as práticas e o perfil profissional docente, além da construção da identidade. Concluiu-se que as propostas de formação continuada, promovidas pelos governos desse novo século, são dedicadas à contribuição do enriquecimento das ações pedagógicas em sala de aula; ao mesmo tempo, falta ainda ofertar conhecimento teórico-científico a esses professores.

\section{UM NOVO SÉCULO PARA A FORMAÇÃO CONTÍNUA}

Os anos iniciais do século XXI foram marcados, no setor educacional, por um leque de propostas. Algumas delas já iniciadas no governo do então presidente Fernando Henrique Cardoso (1995 a 2002) como as Diretrizes Curriculares Nacionais (DCN) e o Plano Nacional de Educação (PNE) de 2001 a 2010, por exemplo. A necessidade de priorizar o crescimento de programas na formação continuada e em planos e ações de qualificação docente fez com que os governos e responsáveis pelo setor educacional do País repensassem suas estratégias. No entanto, tratavam-se de governos que acabaram cedendo aos interesses econômicos e às pressões políticas da época, gerando um estado de crise permanente.

Durante o primeiro mandato do presidente Lula (2003 - 2006), o Governo reconhecia que os cursos de formação de professor eram de péssima qualidade e responsabilizou as universidades federais por não se interessarem pela formação do professor, além de lembrar que o salário do docente no Brasil não tornava a profissão produtiva. (GHIRALDELLI JR., 2009). Sua proposta era a de um governo popular, baseada em ações e programas que prometiam muito às classes menos favorecidas. Levantou a bandeira da igualdade social e a da inserção de um número maior de pessoas em universidades.

Para a preparação docente, a exigência de formação em curso superior de licenciatura plena para os professores da Educação Básica, instituída pela LDB 9495/96, fez com que os cursos de formação se expandissem por todo o País, no entanto a preocupação seria com a qualidade desses cursos o que poderia e pode ocasionar uma deformação na formação inicial e continuada. A bandeira levantada pelo Governo, em seus discursos sobre as políticas educacionais, propunha uma formação continuada que visasse contribuir com o desenvolvimento profissional do professor. 
As iniciativas tomadas pelo Governo Federal em relação às estratégias abrangentes de formação continuada visavam sanar o problema do fracasso na Educação, gerado por um longo sistema de desvalorização da carreira docente. Essas ações tendiam a elevar a qualidade do ensino público oferecido em todo o País. $\mathrm{O}$ aumento dos investimentos e programas voltados à formação continuada de professores tornou-se uma estratégia política constante adotada pelo poder público.

Segundo Dourado (2015), a formação continuada decorre da concepção do desenvolvimento profissional. Assim, a formação continuada é necessária, não apenas para aprimorar a ação profissional, mas também para fazer e dar sentido à profissão docente. A LDB 9495/96 garante a formação continuada de professores como aperfeiçoamento profissional com direito a licenciamento periódico e remuneração.

Para Pimenta,

[...] no que se refere à formação contínua, a prática mais frequente tem sido a de realizar cursos de suplência e/ou atualização de conteúdos de ensino. Esses programas têm se mostrado pouco eficientes para alterar a prática docente e, consequentemente, as situações de fracasso escolar, por tomarem a prática docente e pedagógica escolar nos seus contextos. Ao não colocar como ponto de partida e chegada da formação, acabam por, tão somente, ilustrar individualmente o professor, não the possibilitando articular e traduzir os novos saberes em novas práticas (PIMENTA, 2005, p. 2).

Visando transformar esta ação e colocar em prática a atualização e o desenvolvimento da qualificação docente, foram instituídos planos, programas e ações que objetivam sanar as dificuldades e a deformação do professor com formação inicial e em efetivo exercício. Para Gatti (2012), essas políticas podem ser qualificadas como políticas compensatórias, que procuram alterar algumas situações e circunstâncias dos cursos formadores de professores, mas que, ainda não atingiram o cerne do problema e o coração das instituições.

\section{PROGRAMAS DE FORMAÇÃO CONTINUADA: SEUS MÉTODOS E OBJETIVOS}

O quadro abaixo delineia, de forma resumida, os programas de formação continuada voltados aos professores dos anos iniciais do Ensino Fundamental, desenvolvidos no Brasil desde o início do século XXI. Cada um desses programas será descrito e analisado, mais à frente, criticamente, em seus objetivos e ações. 


\begin{tabular}{|c|c|l|}
\hline Plano & Ano & \multicolumn{1}{|c|}{ Metas } \\
\hline GESTAR I & $2000-2003$ & $\begin{array}{l}\text { Investir na capacitação dos professores, dos anos iniciais do } \\
\text { Ensino Fundamental, em Língua Portuguesa e Matemática. }\end{array}$ \\
\hline PROFA & 2001 & $\begin{array}{l}\text { Oferecer técnicas de alfabetização aos professores } \\
\text { alfabetizadores. }\end{array}$ \\
\hline GESTAR II & 2004 & $\begin{array}{l}\text { Estender a formação continuada de professores de Português } \\
\text { e de Matemática da segunda fase do Ensino Fundamental. }\end{array}$ \\
\hline Formação Continuada & 2004 & $\begin{array}{l}\text { Contribuir com a melhoria da formação dos professores da } \\
\text { Educação Básica nas áreas de Alfabetização, Linguagem, } \\
\text { Educação Matemática e Científica, Ciências Humanas e } \\
\text { Sociais, Artes e Educação Física. }\end{array}$ \\
\hline PROINFANTIL & 2005 & $\begin{array}{l}\text { Capacitar e titular os professores que atuam na Educação } \\
\text { Infantil sem a devida formação. }\end{array}$ \\
\hline PRÓ-LETRAMENTO & 2007 & $\begin{array}{l}\text { Aperfeiçoar o trabalho docente no ensino de Língua } \\
\text { Portuguesa e Matemática nos anos iniciais do Ensino } \\
\text { Fundamental. }\end{array}$ \\
\hline PARFOR & 2009 & $\begin{array}{l}\text { Qualificar os professores das séries iniciais da Educação } \\
\text { Básica e incentivar a licenciatura para professores sem a } \\
\text { formação adequada. }\end{array}$ \\
\hline PNAIC & 2012 & $\begin{array}{l}\text { Estender a formação continuada aos professores dos anos } \\
\text { iniciais do Ensino Fundamental que assegurem plena } \\
\text { alfabetização. }\end{array}$ \\
\hline
\end{tabular}

Fonte: Quadro construído pelas pesquisadoras baseado em publicações do MEC.

O período delimitado no quadro, com um recorte das políticas educacionais voltadas para a formação continuada dos professores no século XXI, equivalente a mais de uma década, apresenta programas instituídos nos governos dos presidentes Fernando Henrique Cardoso (1995 - 2002), Luiz Inácio Lula da Silva (2003 - 2010) e Dilma Rousseff (2011 - 2016), agora representada pelo seu vice-presidente Michel Temer (2016-2018). O recorte político delineado pelo texto é recheado de acontecimentos e propostas que se relacionam diretamente às questões sociais, como à Educação, por exemplo. A transição de líderes e de partidos políticos ocorrida no Brasil, nas primeiras décadas do século XXI, mostra que a opinião e a escolha da sociedade colocaram no governo, primeiramente, um líder popular com ideias e ações sociais que ofereceram mais oportunidades às classes menos favorecidas. A continuidade desse governo, ainda por escolha da maioria da população brasileira, elegendo a primeira presidente mulher do País, foi então interrompida quando a acusação de crime de responsabilidade tirou-a da presidência, dando a seu vice Michel Temer o cargo de presidente do País. A conturbação política atual em que vivemos é percebida em todos os setores sociais da Nação. A construção 
e a continuação de programas de formação de professores para o desenvolvimento e qualidade do ensino público parecem permanecer em um ritmo lento de propostas e ações.

No Governo Lula, houve um investimento na Educação Superior, por meios dos projetos de expansão universitária. A Universidade cresceu em número de vagas, oportunizando maior inclusão na Educação Superior. Contudo, ainda, a universidade brasileira se depara com muitas dificuldades, iniciadas pela inserção histórica na sociedade capitalista. Os recursos são poucos e muita coisa ainda precisa de ser feita para que se alcance uma universidade democrática e de qualidade, para todos que a desejarem.(BORGES, AQUINO e PUENTES, 2011, p. 109)

Em relação à formação contínua de professores, o que se espera, independentemente de governo, partido ou proposta política é que haja, continuamente, a valorização da ação, qualificação e prática docentes. Vale ressaltar que, observando os resultados obtidos pelo professor em um ensino de qualidade, constata-se a necessidade do atendimento a duas condições básicas na sua profissão: a primeira diz respeito à qualidade do conteúdo do que ensina no processo de formação; e a segunda, à valorização do conteúdo que se recebe. Para a concretização dessas habilidades, faz-se necessária a devida valorização de sua formação e o investimento contínuo nessa prática.

Algumas dessas propostas estão descritas abaixo e foram analisadas sistematicamente, visando compreender seus objetivos e métodos. Para explicitar melhor cada um desses programas, além das análises de sua implantação e de seus objetivos, também descrevemos sobre seus métodos e possíveis resultados. Esse mapeamento visa contribuir e enriquecer o estudo e, consequentemente, a melhor compreensão de cada uma dessas propostas de formação continuada.

\section{O PROFA}

Logo que se iniciou o século XXI, a Secretaria de Educação Fundamental do Ministério da Educação (SEF/MEC) lançou, em dezembro de 2000, o Programa de Formação de Professores Alfabetizadores (PROFA), sendo colocado em prática no início de 2001, e tendo como objetivo oferecer novas técnicas de alfabetização a esses professores. Esse foi o primeiro Programa com foco específico na formação continuada de professores dos anos iniciais do Ensino Fundamental, apesar de se falar muito em formação de professor em serviço desde a década de 1960. O curso tinha como base o construtivismo levantado pelas autoras Emília Ferreiro e Ana Teberoski ${ }^{1}$ sobre as transformações nas práticas de ensino da leitura e escrita.

\footnotetext{
${ }^{1}$ As autoras partem do pressuposto da teoria piagetiana de que todo conhecimento possui uma origem e da concepção de alfabetização por construção de níveis silábicos e alfabético.
} 
Para Campos (2006, p. 37), o Programa foi desenvolvido "na tentativa de solucionar problemas evidenciados por estatísticas que alarmam educadores e sociedade, em geral, e em oposição a uma escola considerada por muitos educadores como conteudista".

O Programa era resultado de um processo iniciado com o lançamento dos Parâmetros Curriculares Nacionais (PCNs), estabelecido por convênios com as Secretarias de Educação e organizações já participantes do programa Parâmetros em Ação. O curso anual era aplicado em uma carga horária de 160 horas divididas em três módulos com encontros presenciais do professor-formador com os professores-cursistas e voltado à qualificação e preparo desses docentes utilizando-se de materiais escritos, coletâneas de textos e vídeos.

Uma das finalidades do Curso era reunir teoria e prática fazendo, desses, requisitos importantes para caracterizar o curso como um programa de formação continuada de qualidade. Dourado (2015) afirma que, durante o processo formativo, deverá ser garantida efetiva e concomitante relação entre teoria e prática, ambas fornecendo elementos básicos para o desenvolvimento dos conhecimentos e habilidades necessários à docência. Entendemos que a formação contínua é parte de um processo de reflexão da prática escolar e que, dela, resultam melhores professores e estudantes. Por essa razão, a busca por programas e ações voltados à formação docente é sempre tão almejada.

Segundo a proposta do Programa, durante todos os módulos, os professores deviam planejar atividades para serem realizadas com seus estudantes e, depois de aplicadas, discutidas e analisadas em grupo no Curso, além de avaliações sobre seu desenvolvimento ligadas à teoria estudada e à prática aplicada ao final de cada módulo. Ações como essa enriquecem a metodologia docente, pois constroem uma relação entre teoria e prática. No entanto, existe a concepção de alguns autores de que essa separação não existe na formação e na prática docentes. Segundo Perrenoud (2001) “[...] é preciso combater essa dicotomia e afirmar que a formação é uma só, teórica e prática ao mesmo tempo, assim como reflexiva, crítica e criadora de identidade". Nessa mesma lógica, Pimenta acrescenta que,

Diferentemente das demais ciências da educação, a pedagogia é a ciência da prática. Aí está sua especificidade. Ela não se constrói como discurso sobre a educação. Mas a partir da prática dos educadores tomada como a referência para a construção de saberes - no confronto com os saberes teóricos (PIMENTA, 2000, p. 47)

Ainda segundo a autora, “A construção da teoria didática, a partir da prática, demanda a consideração do triângulo didático em situação, ou seja, os contextos sócio- 
teóricos/históricos nos quais a prática ocorre. Trata-se, pois, de tomar a prática enquanto práxis" (PIMENTA, 2000, p. 21). As habilidades propostas pelo Programa demonstram fundamentar as ações em estudos reflexivos da prática. O Curso deixou como contribuição de formação na prática do professor sua transformação baseada em ações orientadas pela teoria e pela reflexão.

No tex to de dissertação realizado por Campos (2006), com orientação do professor José Carlos Libâneo, a autora descreve que sua intenção, ao pesquisar sobre o PROFA e as professoras cursistas desse Programa, era a de verificar o efeito - na prática das professoras e no desempenho escolar dos estudantes -, de um programa de formação continuada destinado especificamente a formar professores alfabetizadores. Na pesquisa feita pela autora em observação a quatro professoras cursistas do Programa, ela conclui que

É possível notar através da pesquisa, que as pessoas reagem de diferentes formas aos mesmos estímulos. Isto possibilita dizer que as orientações do Programa nem sempre funcionaram bem para as quatro professoras, o que precisou (ou ainda precisa) ser melhorado por outros cursos ou por novos aprendizados do professor, à medida que forem participando de outras formações continuadas (CAMPOS, 2006. p. 94)

Dessa forma, o Programa pode ser entendido como uma amplitude de expectativas, no entanto ainda caberia, aos responsáveis pelas políticas públicas educacionais, a construção de desafios e a elaboração de diferentes programas que se propusessem a inserir inovações curriculares para a melhoria da formação contínua e da prática docente.

\section{GESTAR}

Em paralelo, o Programa Gestão de Aprendizagem Escolar - GESTAR I (2000-2003) foi desenvolvido pelo Fundo de Fortalecimento da Escola (FUNDESCOLA) em parceria com o MEC e o Fundo Nacional de Desenvolvimento da Educação (FNDE), instituído no ano de 2001, visando fortalecer as escolas públicas e promover ações de melhoria na qualidade do ensino. Com fundamento na LDB/96 em seu Art. 87, que prevê o oferecimento de programas de formação de professores em serviço, o Programa é destinado à formação continuada de professores dos anos iniciais do Ensino Fundamental. O Programa surgiu após o diagnóstico do PDE (1997) que constatou a necessidade de capacitação dos professores das séries iniciais em Língua Portuguesa e Matemática, de acordo com as Diretrizes Curriculares Nacionais.

Dourado (2015), discorrendo sobre as novas Diretrizes Curriculares Nacionais e a formação continuada, descreve que 
Segundo as novas DCNs, a formação continuada compreende dimensões coletivas, organizacionais e profissionais, bem como o repensar do processo pedagógico, reuniões pedagógicas, cursos, programas e ações para além da formação mínima exigida ao exercício do magistério na educação básica, tendo como principal finalidade a reflexão sobre a prática educacional e a busca de aperfeiçoamento técnico, pedagógico, ético e político do profissional docente (DOURADO, 2015, p. 312)

Dessa forma, as DCNs definem que a formação continuada envolve, além das atividades formativas, a atualização, a extensão e o aperfeiçoamento dos cursos e atividades oferecidas. Nesse sentido, o Programa buscou aperfeiçoar e estender suas propostas e métodos, levando, aos professores da segunda fase do Ensino Fundamental, a mesma proposta de qualificação profissional.

Em 2004, o Programa foi estendido para GESTAR II, agora orientado para a formação continuada de professores de Português e Matemática da segunda fase do Ensino Fundamental, priorizando a melhoria no processo de ensino. O Curso apresenta uma carga horária de 300 horas, sendo dessas 120 horas presenciais e 180 a distância. A proposta do Governo para esse tipo de formação era/é de contribuir para o aperfeiçoamento da autonomia do professor em sala de aula.

O Projeto conta, como principal objetivo, com a ação de provocar transformações e mudar a atitude desses professores frente ao ensino de língua. A metodologia que o Programa incorpora volta-se à transposição da Didática e remete às dificuldades encontradas pelo professor na busca por articular as concepções de teoria e prática concebidas na formação inicial. O estudo dos módulos e a realização das atividades propostas pelo material do Programa, além dos encontros com o formador, estimulam o professor em sua ação docente, cria vínculo com teoria estudada e promove a organização dos planejamentos de ensino.

Os autores Kochhann e Pirola escrevem sobre o Programa tendo por base pesquisa qualitativa e quantitativa. Para os autores, a conclusão é de que

[...] Se, durante o GESTAR, os participantes foram experimentando o gosto de trabalhar com esse tema, assimilando procedimentos vivenciados, acreditamos que estarão posteriormente mais aptos a efetivamente conduzir um trabalho com seus alunos. E, assim como os sujeitos do referido grupo experimental, poderão sair desse programa muito mais preparados, pois tiveram a experiência e vivenciaram no estudo da geometria a possibilidade de uma formação teórica e prática, a qual é base de todo o processo educativo (KOCHHANN, PIROLA, s/d, p. 02)

O trabalho desses autores assenta-se numa pesquisa que elenca os sujeitos, os procedimentos e instrumentos relacionados ao programa GESTAR. O que se conclui é que o 
Programa apresenta um ponto bastante positivo relacionado à realização de oficinas com a presença de um professor-formador que busca orientar a discussão e a socialização das dúvidas e dos anseios que os docentes encontram em sua prática educativa. Em contraponto, seria importante que o Projeto não fosse voltado apenas a disciplinas específicas, mas que abrangesse também os conteúdos de forma geral, além de textos bibliográficos voltados à qualificação e à formação continuada docente.

\section{REDE NACIONAL DE FORMAÇÃO CONTINUADA}

Além dessas ações, é durante o primeiro mandato do governo Lula, em 2004, que foi criada a Rede Nacional de Formação Continuada de Professores. A Rede veio atender ao objetivo de contribuir na melhora da formação dos professores da Educação Básica do ensino público. Seria então uma resposta às necessidades de pesquisa, produção e formação dos professores, visto que não se trataria apenas do término do Ensino Superior e sim de uma proposta para complementar a vida acadêmica dos educadores. Instituída com a finalidade de contribuir com a qualidade do ensino e com a melhora no aprendizado dos estudantes, a Rede, formada pelo Ministério da Educação (MEC), Sistemas de Ensino e os Centros de Pesquisa e Desenvolvimento da Educação, apresentou como áreas de formação a Alfabetização e a Linguagem, a Educação Matemática e a Científica, o ensino de Ciências Humanas e Sociais, o de Artes e de Educação Física.

As instituições de ensino superior públicas, estaduais e federais que integraram a proposta da Rede ficaram responsáveis pela produção dos materiais de orientação para os cursos a distância e semipresenciais, numa carga horária de 120 horas. Dessa forma, elas teriam o papel de atuar em comum para atender às necessidades e demandas do Plano de Ações Articuladas $^{2}$ (PAR). Quanto ao Governo, expressar-se-ia, por meio do MEC, responsável em oferecer suporte técnico e financeiro no papel de coordenador do desenvolvimento do Programa.

$\mathrm{Na}$ apresentação das orientações gerais da Rede Nacional de Formação Continuada de Professores da Educação Básica disponíveis no site $e^{3}$ do programa, estão descritos seus objetivos, diretrizes e funcionamento.

${ }^{2}$ O Plano de Desenvolvimento da Educação, apresentado pelo Ministério da Educação, em abril de 2007, colocou à disposição dos estados, dos municípios e do Distrito Federal, instrumentos eficazes de avaliação e implementação de políticas de melhoria da qualidade da Educação, sobretudo da Educação Básica Pública.

${ }^{3}$ Ver em: <http://portal.mec.gov.br/rede-nacional-de-formacao-de-professores > 
A formação do educador deve ser permanente e não apenas pontual; formação continuada não é correção de um curso porventura precário, mas necessária reflexão permanente do professor; a formação deve articular a prática docente com a formação inicial e a produção acadêmica desenvolvidas na universidade; a formação deve ser realizada também no cotidiano da escola em horários específicos para isso, e contar pontos na carreira dos professores (BRASIL, 2005, p. 5)

De acordo com as diretrizes do documento, a formação continuada é concebida para além da oferta de cursos de atualização ou treinamento em prol de uma formação que tenha como referência a prática docente e o conhecimento teórico. Dessa forma, os programas e ações desenvolvidos no campo da formação continuada precisam ter ou ser mais que encontros presenciais ou a distância com leituras e/ou sugestões de atividades para prática em sala de aula; necessitam ser literalmente formativos e característicos à práxis docente.

Compreende-se, por essa proposta do MEC, um objetivo de permanência e continuidade dado à formação profissional docente. Para Frade (2010), a própria constituição da Rede Nacional de Formação Continuada expressa o reconhecimento de que a formação contínua integra a cultura profissional brasileira. Para a autora, a criação dessa Rede demonstra que, gradativamente, a formação continuada afirma-se na cultura educacional das escolas e secretarias de educação, requerendo ações constantes; ao mesmo tempo instaura uma nova perspectiva de formação a ser discutida pelas universidades de forma cooperativa.

Freitas (2002) aponta que a presença das universidades na elaboração e implementação de propostas de formação continuada é vista como fator positivo, uma vez que o deslocamento das iniciativas de formação, tanto inicial quanto continuada, das universidades para institutos superiores de educação e cursos normais superiores em instituições isoladas privilegiaria um modelo descompromissado com a pesquisa e a formação multidisciplinar sólida. Contudo, Torres alerta para a limitação presente nesse modelo de atuação quando se estabelece um vínculo com as universidades a partir da intervenção em projetos pontuais e "não a partir do compromisso da universidade com a escola pública e com a transformação do modelo educativo vigente" (1998, p. 184).

Dessa forma, o longo caminho traçado pela política educacional para formação continuada chegou ao século XXI carregado de obstáculos a serem definidos. Nossas pesquisas levam-nos a crer que não há ensino de qualidade, nem reforma educativa, nem inovação pedagógica, sem uma adequada formação de professores, o que depende de políticas sérias e investimentos consistentes. Por essa razão, a análise dos programas elencados para a formação continuada faz-se tão presente e necessária ao desenvolvimento da qualificação pedagógica. 


\section{PROINFANTIL}

Faltava, ao Governo, uma ação política que correspondesse à proposta de formação de todos os profissionais da Educação, já estabelecida pela LDB/96, visando garantir a capacitação dos professores em todos os níveis e atendendo ao art. 62 da Lei 9.394/96, que admite como formação mínima para o magistério, a formação em nível médio para professores da Educação Infantil e anos iniciais do Ensino Fundamental. O MEC, em parceria com estados e municípios, propôs, ainda no ano de 2004, mas com início em 2005, o Programa de Formação Inicial para Professores em Exercício na Educação Infantil - Proinfantil.

Assim, o Proinfantil, como política pública de formação docente, foi criado como uma proposta emergencial para adequação da atuação profissional frente às exigências legais vigentes. A implantação do Programa, pelo MEC, deveu-se ao elevado número de professores leigos atuando na Educação Infantil em todo o País. Para Camargo,

O Programa apresenta as mesmas características e organização estrutural do Proformação, Programa de Formação de Professores em Exercício, lançado em 1999 que teve como objetivo promover a formação dos profissionais que atuam nos anos iniciais do ensino fundamental, e que já havia passado por uma avaliação externa, onde fora referendado pelos pesquisadores com um conceito bastante positivo (CAMARGO, 2012, p. 58)

O Programa, contextualizado no quadro das políticas públicas para o setor educacional, apresentou - como principal finalidade, - a capacitação e titulação dos professores que atuassem nas instituições de Educação Infantil sem a devida formação. No entanto, tratava-se de um curso em nível médio a distância, que objetivava proporcionar aos professores, sem habilitação mínima exigida, o domínio dos conteúdos do Ensino Médio e a formação pedagógica necessária para a melhoria de sua prática profissional. Para Freitas (2007), a oferta de cursos e programas a distância, articulados em polos presenciais nos municípios, representa um avanço, se considerarmos as propostas anteriores de formação a distância de curta duração, desenvolvidas em nosso País.

O Curso dividia as turmas em grupos e era realizado em um período de dois anos contendo um programa de quatro módulos com a duração de seis meses cada. O modo de avaliação dos professores cursistas era feito por meio das instituições em que o professor atuava, não podendo o mesmo se desvincular do tipo de ensino em que trabalhava até o término do Curso.

Camargo (2012) ressalta a importância da sua pesquisa de cunho qualitativo e quantitativo sobre a experiência de um grupo de professores em formação de uma das turmas 
do curso Proinfantil. A autora chama atenção para a quantidade de professores com formação mínima e descreve que, segundo os dados constatados em sua pesquisa analítica, a percepção das cursistas quanto ao curso é classificada da seguinte forma:

[...] melhoria do trabalho pedagógico; melhorias da prática em relação ao desenvolvimento - progresso da criança; melhorias do aspecto pessoal (CAMARGO, 2012, p. 87 -88).

Por meio desse estudo, tornou-se clara a compreensão de que os professores, descritos nesta pesquisa, não citaram o Programa de Formação Continuada como processo contínuo de conhecimento, reflexão crítica ou enriquecimento docente. Para as entrevistadas, a preocupação se voltou mais ao perfil e prática docentes e, quando questionadas sobre o que poderia melhorar no Programa, as entrevistadas também tiveram suas respostas voltadas ao apoio e aspecto pedagógicos.

É necessário superar a concepção de formação continuada apenas como modelo de profissionalização. Considerando os referenciais das políticas públicas pela formação de professores, a '[...] formação reflexiva deve ser incorporada à formação do professor de modo que potencialize a ação e a reflexão, tidas como necessárias ao desenvolvimento de uma prática educativa competente e problematizadora". (MAZZEU, 2011, p. 158)

Com o decorrer dos anos em que o Programa foi aplicado, algumas mudanças ocorreram no campo de formação dos tutores, preparação dos grupos formados e revisão dos materiais utilizados pelo Curso. A cada ano, era maior a extensão por todo o País, porém a ideia inicial e o objetivo do Proinfantil eram os mesmos.

As propostas de formação continuada e qualificação dos professores da Educação Básica apontam para transformações importantes na Educação. Em relação ao ensino infantil, a valorização da dimensão educativa e da instrução de creches e pré-escolas definiu uma nova formação específica para os docentes que atuam nessa etapa educacional. Contudo, a proposta estabelecida pela política educacional do Programa refere-se mais à profissionalização docente do que à própria formação continuada como reflexão sobre o papel e as competências do educador infantil.

\section{PRÓ-LETRAMENTO}

Em 2007, foi instituído, sob a coordenação da Rede Nacional de Formação Continuada, o Pró-Letramento, passando a ser oferecido em todo o País até o ano de 2010, compreendendo as áreas de Alfabetização e Linguagem e Matemática. O Programa foi criado pelo MEC com a 
finalidade de aperfeiçoar o ensino de Língua Portuguesa e Matemática servindo de apoio aos docentes em seu trabalho pedagógico nos anos iniciais do Ensino Fundamental. É importante situar que a origem dessa ação de formação continuada do Governo Federal está diretamente relacionada com o projeto político que amplia, de oito para nove anos, a duração do Ensino Fundamental no País. (JOSÉ, 2012, p. 36)

O Programa era destinado a atender dois níveis: formação de tutores e formação de professores, tornando-se assim de caráter semipresencial. O Governo parecia ver, na educação a distância, uma modalidade favorável à formação continuada dos professores da Educação Básica que poderiam minimizar sua falta de especialização. Essa estratégia formativa foi apresentada com o objetivo de envolver a todos os docentes em uma rede de construção de conhecimentos que gerasse novos entendimentos e perspectivas favoráveis às práticas de ensino-aprendizagem.

Segundo o próprio site $e^{4}$ do Pró-Letramento no portal do MEC, este é um programa de formação continuada de professores para a melhoria da qualidade de aprendizagem de Leitura/Escrita e Matemática nos anos/séries iniciais do Ensino Fundamental com a duração de 120 horas estendidas em um prazo de 8 meses, utilizando de material impresso e vídeos. A parceria do Programa englobava, além do próprio MEC, as universidades da Rede Nacional de Formação Continuada e os sistemas de ensino. Rocha (2010) explica que os programas de formação desenvolvidos pelo MEC, analisados em seu estudo, dentre eles o Pró-Letramento, apresentam como eixos orientadores a valorização profissional e dos saberes docentes.

José (2012, p. 42), por meio de sua pesquisa no trabalho de dissertação para a Faculdade de Educação da UFMG, sobre o Programa, conclui que “[...] o Pró- Letramento é reconhecido como uma proposta de formação continuada fundamentada nos princípios da racionalidade prática, que confere importância à prática reflexiva dos professores”. Para a autora,

O reconhecimento dos saberes dos professores, sua valorização profissional e a ênfase nas dimensões mais práticas do ensino aparecem como avanços contidos nessa proposta de formação. Entretanto, podem-se identificar também algumas limitações importantes contidas na própria perspectiva de prática reflexiva adotada pelo programa de formação. No paradigma da racionalidade prática, não se defende que o fazer do professor seja apenas empírico e intuitivo e distanciado do conhecimento científico, mas que seu fazer se sustente a partir de seus saberes - que são plurais, heterogêneos e oriundos de várias fontes: da história de vida do professor; da cultura escolar anterior; dos conhecimentos adquiridos na universidade durante a formação inicial; dos conhecimentos chamados curriculares, que dizem respeito aos programas, guias e matérias escolares; de sua própria experiência e da experiência de seus pares; da tradição da profissão. Portanto, saberes compostos de diversas teorias, concepções e técnicas que são utilizadas

\footnotetext{
${ }^{4}$ Ver em: <http://portal.mec.gov.br/pro-letramento>.
} 
conforme a necessidade, de acordo com os objetivos que os professores procuram atingir (JOSÉ, 2012, p. 44).

Entre as demais propostas do Pró-Letramento, estabelecer a formação continuada junto a uma ação reflexiva, atrelada à realidade encontrada na formação inicial, parece distante quando se baseia em um programa munido de atividades práticas que devem ser aplicadas na ação docente acompanhadas apenas de instrução de seus tutores. O programa, em sua metodologia, demonstra uma preocupação central no "como fazer", no "saber técnico", considerando, razoavelmente, a dimensão teórica. Métodos como esse, em um programa de grande extensão, podem ser justificados pela necessidade em alcançar, rapidamente, os objetivos relacionados a índices, como resultados de desempenho e habilitação rápida, por exemplo. De toda forma, formação não se concretiza em formação sem suporte teórico para tal. Ademais, a revisão dos currículos, dos materiais de apoio ao trabalho dos professores e das próprias metodologias de ensino, faz parte desse Programa, diante da defasagem de rendimento dos estudantes da Educação Básica, em relação às expectativas de aprendizagem apontadas nas avaliações nacionais de larga escala e, assim, o Pró-Letramento passa a ser articulado à Provinha Brasil - Avaliação da Alfabetização Infantil - então lançada pelo MEC.

\section{O PARFOR}

Ainda visando organizar a formação inicial e continuada dos professores da rede pública do País, o Governo, instituiu em janeiro de 2009, como programa emergencial, pelo Decreto 6.755, a Política Nacional de Formação de Profissionais do Magistério da Educação Básica (PARFOR).

O PARFOR é resultado de uma ação conjunta do MEC, das Instituições Públicas de Educação Superior (IPES), das Secretarias de Educação de Estados e Municípios e da Coordenação de Aperfeiçoamento Pessoal de Nível Superior (CAPES), no âmbito do PDE Plano de Metas Compromisso Todos Pela Educação. O PARFOR Presencial é destinado aos professores da rede pública da Educação Básica com objetivo principal de qualificar os professores das séries iniciais e incentivar a segunda licenciatura para os professores que atuavam em outras disciplinas, sem a formação adequada para tal (PAULO, 2012). Para a autora, o Plano passou por um caminho de quebra de paradigmas, de rompimento com aquilo que estava sendo posto e de confronto com a realidade das universidades públicas e a escola pública brasileira. Segundo ela, o Plano apresentou 
[...] um ganho significativo em contraponto com o artigo 62, que reserva para a educação infantil apenas a exigência do antigo curso Normal, como formação obrigatória. Dessa forma, a qualificação se amplia e se estende para todo profissional da educação da escola básica (PAULO, 2012, p. 5)

O PARFOR surge em forma de projeto de lei, viabilizando a formação universitária do docente para todas as etapas do Ensino Básico. Tal política reflete, de forma clara, o compromisso do MEC com a organização da formação continuada dos professores da Educação Básica. Os cursos são ofertados nas modalidades presenciais e a distância, abrangendo, dentro da formação inicial: a primeira licenciatura, segunda licenciatura e formação pedagógica; na formação continuada: cursos de extensão e aperfeiçoamento (entre 30 e 220 horas) e cursos de especialização com a duração mínima de 360 horas, pelo MEC/Plataforma Freire.

Tanto o PARFOR quanto a Universidade Aberta do Brasil (UAB) têm destaque comum em sua organização: a ênfase na utilização de recursos e tecnologias da educação a distância e a formação prioritária oferecida aos profisssionais em serviço. Para Gatti (2008), nos últimos anos, a educação a distância ou mista (presencial/a distância) tem sido muito valorizada pelas políticas públicas educacionais, tornando-se a modalidade de formação mais escolhida tanto em nível federal quanto estadual e municipal. Seu uso tem sido justificado "até como uma forma mais rápida de prover formação" (2008, p. 65), pois as tecnologias disponíveis permitem a flexibilização dos horários de estudos e os tornam mais compatíveis com os diversos tipos de jornadas de trabalho dos professores.

Os cursos oferecidos com a utilização da Educação a Distância (EAD) têm garantido maior acesso tanto à formação inicial quanto à formação continuada, além da diminuição das despesas governamentais com a formação. Entretanto, sempre é questionada a sua eficiência.

Barreto (2015) aponta inúmeros fatores como dificuldades do modelo de formação EAD, porém, existem outros entraves nos programas de formação - as condições recentes de sua ampliação, os desequilíbrios históricos que, apesar das reformas, mantêm-se praticamente inalterados e a maior lacuna talvez seja "a dificuldade de espaços híbridos de formação que propiciem a integração de componentes acadêmicos, teóricos, pedagógicos e de saberes construídos no exercício da profissão (...)”(BARRETO, 2015, p. 688).

Essa medida propôs ainda ações formativas, objetivando articulação entre as Instituições de Ensino Superior e as redes de ensino da Educação Básica com projetos pedagógicos promovidos pela CAPES propondo inovações nas matrizes curriculares e formativas.

Outra inovação de tal política foi a orientação para a criação de Fóruns Estaduais Permanentes de Apoio à Formação Docente, com representantes das várias instituições, para articular planos estratégicos a serem formulados em 
coparticipação, a partir de diagnósticos, assim como acompanhá-los e avaliálos. Os secretários estaduais de Educação devem presidir esses fóruns em seus respectivos estados. O Ministério da Educação (MEC) terá a incumbência de aprovar o plano estratégico, apoiando as ações de formação por meio de concessão de bolsas de estudo e bolsas de pesquisa para professores, provendo auxílio a projetos relativos às ações propostas e aprovadas, como também dando apoio financeiro aos estados, Distrito Federal, municípios e instituições públicas para a implementação dos projetos (BORGES, AQUINO e PUENTES, 2011, p. 107).

A análise feita por Gatti sobre essa proposta, considera, no entanto, que ainda

[...] há pontos específicos, relativos a essa ação política que devem ser considerados para seu aperfeiçoamento, como os aspectos de gestão financeira, aspectos administrativos, clareza nas responsabilidades a serem compartilhadas pelas instituições envolvidas, melhor comunicação entre essas entidades e clareza de papéis e demandas, e, especialmente em face das características dos professores-alunos, melhor preparação ou eleição dos professores que serão formadores e que necessitam de uma visão mais concreta sobre a educação básica - seus objetivos, o alunado, os conteúdos, as necessidades didáticas, as condições das escolas; trabalho mais intenso para evitar as desistências (GATTI, 2012, p. 10).

Para o acompanhamento desses professores em relação aos cursos, a Política Nacional de Formação dos Profissionais do Magistério da Educação Básica (BRASIL, 2009, p.1), estabeleceu que "[...] na formação inicial dar-se-á preferência ao ensino presencial, conjugado com o uso de recursos e tecnologias a distância, e na formação continuada utilizar-se-ão, especialmente, recursos e tecnologias de educação a distância".

A discussão da formação remete-nos ainda à temática das novas tecnologias e da educação a distância, estreitamente relacionada à política de formação continuada e da formação em serviço nas políticas atuais, que vem expandindo-se em ritmo acelerado por todo país (FREITAS, 2012, p. 149).

Entre os aspectos que se destacam tanto na organização do PARFOR, quanto nos outros programas de formação, seja ela a distância ou presencial, estão os relacionados à ênfase na utilização de recursos e tecnologias da Educação como também os da formação prioritária oferecida aos profissionais em serviço. Por essas questões, vê-se a preocupação do Governo em atender à necessidade de erradicação de profissionais despreparados.

Com uma nova eleição e numa outra década, o governo Dilma manteve e ampliou programas já iniciados pelo seu antecessor, além de criar outros novos. No entanto, o novo Governo também estabeleceu algumas modificações organizacionais; dentre essas, também havia reorganizações no MEC. 
Em meio às mudanças realizadas no Ministério da Educação, destacou-se a extinção da Secretaria de Educação a Distância (SEED), criada em 1996. Segundo o próprio MEC, a medida fazia parte de um novo processo de reestruturação, que ainda estava em andamento. Os projetos decorrentes da SEED foram transferidos para a Secretaria de Educação Básica e Ensino Superior. A ideia era de que, com o crescimento da modalidade, ela pudesse ser dirigida pelas secretarias convencionais, utilizando das mesmas medidas para modalidades presenciais e a distância.

No mesmo ano, foi reestruturada e ampliada a Rede Nacional de Formação de Professores da Educação Básica (2004) para Rede Nacional de Formação Continuada dos Profissionais do Magistério da Educação Básica. Com isso, os cursos de aperfeiçoamento, em modalidades a distância e os semipresenciais, passaram a ser das seguintes áreas: Educação Matemática e Científica, ensino de Ciências Humanas e Sociais, Artes, Educação Física e Educação Infantil.

\section{PNAIC}

Ao refletir os dados existentes deixados pela formação inicial, foi lançado, em 2012, o maior programa de formação continuada para professores da Educação Básica no governo do PT. O Pacto Nacional pela Alfabetização na Idade Certa (PNAIC) - em um compromisso assumido pelos governos federal, dos estados e municípios e do Distrito Federal - tem como objetivo assegurar a plena alfabetização de todas as crianças de até oito anos de idade, ao final do $3^{\circ}$ ano do Ensino Fundamental. (BRASIL, 2015)

O eixo do Programa é destinado à formação continuada de professores dos anos iniciais do Ensino Fundamental contribuindo para a alfabetização e o letramento. O Pacto é realizado com encontros presenciais contando com tutores, professores formadores e professores cursistas. Compreende um conjunto integrado de programas, matérias e referências curriculares pedagógicas, disponibilizados pelo MEC, complementados por materiais didáticos e avaliação.

O PNAIC está respaldado pela Política Nacional de Formação de Profissionais do Magistério da Educação Básica pelo Decreto n. 6.755/2009. Ao instituir o Pacto, o Governo deixou clara sua preocupação com a complementação da formação continuada de professores alfabetizadores como política nacional. O compromisso do Pacto corresponde a um programa de estratégias do Governo relacionado às metas de alfabetização para todos. O Documento assegura que as propostas de formação continuada se constituem em um conjunto de atividades 
desenvolvidas ao longo de toda carreira docente e, por essa razão, visa à melhoria da qualidade de ensino e aperfeiçoamento dos professores.

O Pacto, ainda em vigência por todo o País, amplia a cada ano os níveis de ensino dos professores cursistas e os conteúdos trabalhados. O Programa estabelece ainda uma bolsa remunerada para todos os participantes, distribuídas em valores adequados ao nível de participação de cada um: tutores, formadores ou cursistas. Como metodologia do Programa, são realizados encontros semanais para a leitura e orientação de práticas educativas e, para os tutores, encontros frequentes para demonstração da avaliação e desempenho de cada grupo de formandos. Como outros programas de formação já descritos anteriormente, o Pacto também visa à qualificação dos docentes por meio de atividades pré-estabelecidas contanto com amparo teórico. Esse aspecto apresenta ser o ponto em comum de muitos dos programas aqui descritos e, a essa observação, toda dedicação na análise do texto.

Em seu trabalho dissertativo para PUC-SP, Munhoz (2016) descreve sobre sua pesquisa qualitativa e quantitativa em relação a essa política de formação. A autora relata sua observação realizada com cursistas do Programa e afirma que foi notória a percepção da expectativa positiva e o interesse demostrando pelo grupo com a proposta de formação do Pnaic. O problema levantado pela pesquisadora era o de identificar as influências do Pnaic na prática do professor. De acordo com sua pesquisa, os professores cursistas afirmaram sentir um entusiasmo com esse Programa que ainda não haviam sentido com programas de formação oferecidos a eles anteriormente, pois o Pnaic lhes possibilitava colocar seus próprios conhecimentos em prática.

A autora conclui sua pesquisa com uma análise positiva da proposta de formação oferecida pelo Pnaic à prática do professor. Para ela, os resultados da entrevista e observação realizados para a construção de seu texto mostraram que os professores, gestores, e a escola como um todo, reconhecem, nesse Programa, a oportunidade de enriquecer seus conhecimentos e sua prática docente. Os professores alfabetizadores entrevistados afirmaram compartilhar com toda a escola a experiência adquirida no Curso.

Esse processo de formação oferecido por essa política educacional parece contribuir na prática e na socialização dos professores cursistas. Quando há o envolvimento de um grupo e um pensar na ação docente, simultaneamente ocorre uma reflexão da prática e dos métodos que caracterizam o perfil do professor. Para Tardif,

[...] se assumimos que os professores são atores competentes, sujeitos ativos, deveremos admitir que a prática deles não é somente um espaço de aplicação de saberes provenientes da teoria, mas também um espaço de produção de saberes específicos oriundos dessa mesma prática (TARDIF, 2014, p. 234). 
Dessa forma, compreendemos que o Programa apresenta influências positivas na prática docente e que, ainda, tem muito a contribuir na formação continuada de professores dos anos inicias do Ensino Fundamental em exercício. O que se espera, ainda, são ações do poder público que estendam esse e outros tipos de formação contínua a todos os níveis docentes. Vale destacar que, por certo, as bolsas de estudo oferecidas para os atores do processo no Pnaic também favoreceram o sucesso do Programa.

Por outro lado, Gatti e Barreto (2009) contestam o modelo de formação do Programa, em relação a sua efetividade, pelo fato de se tratar de uma formação em que os especialistas das Instituições de Ensino Superior, das universidades, são designados para formar os professores formadores, que por sua vez formam os professores orientadores de estudos, que formam os professores que atuam nas salas de aula de alfabetização, com o objetivo de garantir a aprendizagem dos estudantes. Para Gatti e Barreto (2009, p. 202) esse modelo "percorre os diferentes escalões da administração dos extensos sistemas de ensino, corpo técnicopedagógico, supervisores regionais, professores especialistas". Conforme as autoras, o modelo de formação admite o envolvimento de um número significativo de participantes, mas não apresenta os mesmos resultados em termos de implicações pedagógicas. Nessa perspectiva de formação, diferentes autores coincidem em afirmar que os saberes experienciais dos professores nem sempre são levados em conta.

Assim, apontando as limitações presentes na proposta de formação continuada de alfabetizadores, deparamo-nos, ainda, com a mensuração da aprendizagem dos estudantes, tomando, como parâmetro, os indicadores internacionais, com exigência de melhores resultados dos estudantes, para cumprir as metas estabelecidas nos compromissos firmados com agentes internacionais, por exemplo.

Num momento de crise em nosso País e mediante as restrições orçamentárias para a Educação, tememos a descontinuidade ou a suspensão de programas importantes para a formação, descumprindo as metas do PNE (2014/2024).

\section{CONSIDERAÇÕES FINAIS}

Desde que se iniciou o século XXI, o MEC tem investido na política de ações para formação continuada de professores em exercício oferecendo cursos em parceria com estados, municípios e universidades. O que é esperado pelos responsáveis dessa formação é que os professores sejam instigados ao exercício e à reflexão de novas práticas pedagógicas. 
Atualmente, as políticas educacionais de formação continuada estão sendo guiadas, principalmente, por resultados obtidos em avaliações e dados da qualidade do ensino.

A formação continuada, segundo Manzano (2008), contempla a prática reflexiva. O pouco que se tem investido na formação inicial e a necessidade de preparar os professores e os estudantes, a questão da economia mundial possibilitaram uma necessidade de formação constante. A formação continuada viria a reparar as lacunas deixadas pela formação inicial e a redefinição das propostas de qualificação docente.

Dos programas aqui apresentados, a maioria é voltada para os professores dos primeiros anos da Educação Básica ou do Ensino Fundamental o que demonstra uma atenção especial do Governo nessa etapa de ensino, destacando, que é nesse período, que acontece a alfabetização. O governo do PT, representado por Lula e Dilma, levantou sua bandeira contra o analfabetismo no País e, talvez, seja por essa razão que programas de formação continuada foram tão evidenciados desde o início do século XXI.

É nesse contexto que se estruturam as políticas de formação de professores no nosso País. A concepção da oferta de programas de formação continuada que utilizam apenas de meios tecnicistas ou a distância como método de qualificação ainda é um problema a ser superado pelas políticas públicas educacionais.

Entendemos, pois, que a política do governo Lula presente no novo século demonstrou preocupação em atender às necessidades dos professores quanto ao conhecimento e à prática docente. Governo esse eleito, em sua maioria, pelas propostas de igualdade social, levantou, para a Educação, a bandeira de uma formação de qualidade e propôs estabelecer ações que fossem correspondentes aos objetivos traçados em seus discursos. O sucesso de sua estratégia de governo garantiu que sua representação, e de seu partido, estivessem à frente da federação nacional até meados da segunda década do século XXI, interrompidos por uma cassação política prontamente entendida como um golpe de governo contrário à igualdade social das classes menos favorecidas. No entanto, apesar da revolta e indignação a essas ações políticas, esse tema caberia à análise de uma nova pesquisa.

A análise de todo esse processo histórico acerca da implantação da formação continuada no Brasil mostra que, tanto seus conceitos quanto suas finalidades, foram mudando ao longo do tempo, ligadas ao contexto econômico e político do País. Por meio dessas mudanças, destacamse também as diferentes concepções acerca do termo formação. A aquisição de novas habilidades e conhecimentos, hoje relacionados a essa concepção, antes era vista e classificada como treinamento, reciclagem e capacitação. Cabe, no entanto, adequar à compreensão de que a formação continuada de professores também é composta por uma base teórico-científica que 
possibilita desenvolver o senso crítico reflexivo e o lado pesquisador do professor. Os programas de formação continuada de professores se tornam essenciais para o desenvolvimento de ações como essas visando promover a qualidade docente, a qualidade no ensino, na escola e na Educação, numa perspectiva inovadora. Para Tardif (2002), a formação de professores acarreta certas mudanças substanciais nas concepções e nas práticas vigentes.

Ao promover programas e propostas de formação continuada, as políticas públicas educacionais estão oferecendo também uma aprendizagem contínua importante para o desenvolvimento profissional docente e para sociedade. Shulman (2005) aponta que as iniciativas voltadas para a reforma educativa estão em evidência e devem defender o aumento do nível de profissionalismo dos professores em relação ao que o autor destaca como conhecimentos básicos para atividade de ensino.

Quanto à contribuição da formação continuada à identidade profissional, entendemos que esse é um processo de construção e de revisão constantes. A formação inicial seria então o primeiro passo dado para a escolha da profissão e uma base de conhecimentos a ser utilizada na ação docente. A formação continuada contribui na reafirmação dessa escolha, no aprimoramento do conhecimento e no desenvolvimento constante dessa ação. Poderíamos então afirmar que, o processo de formação continuada configura-se no sentido de reconstrução do professor enquanto autor de sua prática, no domínio de seus conhecimentos e o fundamento na consciência reflexiva docente.

Destarte, se por um lado as políticas de formação continuada de professores têm trazido benefícios e avanços para a área; por outro, vemos descontinuidade dos programas, uma vez que são programas de Governo e não de Estado; priorização dos aspectos técnicos e da prática - o como fazer - em detrimento da formação teórica, o que impede a superação da dicotomia entre a teoria e a prática para o profissional docente.

À esteira de Saviani (2014), entendemos que a organização de um sistema educacional coeso e forte garantirá a continuidade dos cursos de formação de professores com investimentos voltados para políticas de Estado e, por isso, mais contínuas e eficazes.

De modo geral, compreendermos que esse novo século trouxe propostas de formação continuada, por parte das políticas públicas, há muito esperadas e que buscam envolver os professores, oferecendo a eles métodos e conceitos voltados à prática docente. Os frequentes programas oferecidos pelo Governo, apesar das limitações, demostram grande preocupação com a formação docente e a qualidade do ensino. 


\section{REFERÊNCIAS}

ALVARADO-PRADA, Luiz Eduardo; FREITAS, Thaís Campos; FREITAS, Cinara Aline. Formação continuada de professores: alguns conceitos, interesses, necessidades e propostas. Rev. Diálogo Educ., Curitiba, v. 10, n. 30, p. 367-387, maio/ago. 2010. Disponível em: <http://www.redalyc.org/articulo.oa?id=189114449009>. Acesso em: jun. 2017.

BARRETTO, Elba. Políticas de formação docente para a educação básica no Brasil: Embates contemporâneos. Revista Brasileira de Educação, v.20; n.62; jul./set. 2015.

BORGES, Maria Célia; AQUINO, Orlando F.; PUENTES, Roberto Valdés. Formação de professores no Brasil: história, políticas e perspectivas. Revista HISTEDBR On-line, v. 42, p. 94-112, 2011.

BRASIL. Lei n. 9.394 de 20 de dezembro de 1996. Estabelece as diretrizes e bases nacionais da educação nacional. Disponível em:

< https://www.planalto.gov.br/ccivil_03/Leis/L9394.htm>. Acesso em: 02 jul. 2016.

BRASIL. Lei n. 12.801 de 24 de abril de 2013. Dispõe sobre o apoio técnico e financeiro da União aos entes federados no âmbito do Pacto Nacional pela Alfabetização na Idade Certa. Disponível em: <http://pacto.mec.gov.br/images/pdf/Formacao/documento_orientador_2015_versao_site.pdf >. Acesso em: 26 jul. 2016.

BRASIL. Ministério da Educação. Pró-Letramento. Apresentação. Orientações gerais. Disponível em: 〈http://portal.mec.gov.br/pro-letramento/apresentacao >. Acesso em: 25 jun. 2016.

BRASIL. Ministério da Educação. Secretaria de Educação Básica. Rede Nacional de Formação Continuada de Professores de Educação Básica: orientações gerais. Catálogo 2005. Disponível em: 〈http://portal.mec.gov.br/seb/arquivos/pdf/Rede/catalg_rede_06.pdf>. Acesso em: 02 jul. 2016.

CAMARGO, Rosimeire Dias de. Proinfantil: ressignificando as práticas pedagógicas na educação infantil. 2012. 120 f. Dissertação (Mestrado em Educação) -Universidade do Estado de Mato Grosso, UNEMAT, 2012. Disponível em:

$<$ http://portal.unemat.br/media/oldfiles/educacao/docs/dissertacao/2012/ rosimeire dias_de_camargo.pdf>. Acesso em: 10 jun. 2017.

CAMPOS, Rosariane Gláucia Mendonça. O Programa de Formação de Professores Alfabetizadores - PROFA e suas implicações pedagógicas: concepção de alfabetização, atuação profissional e resultados obtidos. 2006. 120 f. Dissertação (Mestrado em Educação) Universidade Católica de Goiás, Goiânia.

DOURADO, Luiz Fernandes. Diretrizes Curriculares Nacionais para a formação inicial e continuada dos profissionais do magistério da educação básica: concepções e desafios. Educ. Soc. Campinas, v.36, n. 131, p. 299-324, abr./jun., 2015.

FRADE, Isabel C. A. S. Formadores e professores: discutindo lógicas de ação. Revista Língua Escrita, Belo Horizonte, n. 1, jan. abr. 2007. 
FREITAS, Helena Costa Lopes de. Formação de professores no Brasil: 10 anos de embate entre projetos de formação. Educ. Soc., Campinas, SP, vol.23, no.80, p.136-167, set 2002.

Certificação docente e formação do educador: regulação e desprofissionalização. Educ. Soc., Campinas, SP, vol.24, no.85, p.1095-1124, dez. 2003.

A (nova) política de formação de professores: a prioridade postergada. Educ. Soc., Campinas, SP, v. 28, n. 100, p. 1.203-1.230, out. 2007.

GATTI, Bernadete A. Análise das políticas públicas para a formação continuada no Brasil, na última década. Revista Brasileira de Educação, vol.13, n.37, jan./abr. 2008. Disponível em: $\langle$ http://www.scielo.br/pdf /rbedu/v13n37/06.pdf > . Acesso em: dez. 2016.

Políticas de formação de professores: perspectivas no Brasil. XVI ENDIPE Encontro Nacional de Didática e Práticas de Ensino - UNICAMP - Campinas. 2012.

GATTI, Bernadete; BARRETO, Elba. Professores do Brasil: Impasses e desafios; Brasília, UNESCO, 2009.

GHIRALDELLI JR, Paulo. Filosofia e história da educação brasileira: da colônia ao governo Lula. 2. ed. Barueri, SP: Manole, 2009.

MANZANO, Cinthia Soares. A formação de professores na Revista Brasileira de Educação (1995 - 2005): uma breve análise. In: $31^{\text {a }}$ REUNIÃO DA ANPED, 2008. Anais... Caxambu, MG, 2008, p.1-16. Disponível em: <http://www.anped.org.br/sites/default/files/gt08-4593int.pdf>. Acesso em: 20 junho 2017.

JOSÉ, Lucimara de São. Os efeitos do pró-letramento na formação das professoras alfabetizadoras do município de Conselheiro Lafaiete [manuscrito]. 2012. 196 f. Dissertação (Mestrado em Educação) - Universidade Federal de Minas Gerais, Belo Horizonte MG. Disponível em: <http://www.bibliotecadigi tal.ufmg.br/dspace/bitstream/handle/1843/BUOS8ZKR77/dissertacao_lucimara_22_setembro.pdf? sequence=1>. Acesso em: 10 jul. 2016.

KOCHHANN, Maria Elizabeth Rambo; PIROLA, Nelson Antônio. GESTAR: Os desafios da formação em serviço. Disponível em:

<http://need.unemat.br/4_forum/artigos/maria_elizabeth_1.pdf $>$. Acesso em: jun. de 2017.

LIBANÊO, José Carlos; PIMENTA, Selma Garrido. Formação dos profissionais da Educação: visão crítica e perspectivas de mudança. In: PIMENTA, Selma Garrido (Org.) Pedagogia e pedagogos: caminhos e perspectivas. São Paulo: Cortez, 2006.

MAZZEU, Lidiane Teixeira Brasil. A política educacional e a formação de professores. Reflexões sobre os fundamentos teóricos e epistemológicos da reforma. In: MARSIGLIA, Ana Carolina Galvão (Org.). Pedagogia histórico-crítica: 30 anos. Campinas: Autores Associados, 2011.

MUNHOZ, Neire Sueli. Formação continuada: Estudo da influência do Pnaic na prática dos docentes de Barueri. 2016. 189f. Dissertação (Mestrado em Educação). Pontifícia Universidade Católica de São Paulo. São Paulo. Disponível em: $<$ https://sapientia.pucsp.br/handle/handle/19213?locale=en>. Acesso em: jun. 2017. 
NÓVOA, António (Org.). Os professores e sua formação. Lisboa: Dom Quixote, 1992.

PAULO, Luciana Hallak. Políticas de qualificação no governo Lula/Dilma: reflexões sobre a formação humana. In: XVI ENCONTRO NACIONAL DE DIDÁTICA E PRÁTICAS DE ENSINO, 2012. Anais... Campinas, 2012, p. 2-9. Disponível em:

$<$ http://www.infoteca.inf.br/endipe/smarty/templates/arquivos_template/upload_arquivos/acer vo/docs/3241d.pdf>. Acesso em: 15 jul. 2016.

PERRENOUD, Philippe. Dez novas competências para uma nova profissão. Suíça: Universidade de Genebra, 2001.

PIMENTA, Selma Garrido (Org.). Didática e formação de professores: percursos e perspectivas no Brasil e em Portugal. 3.ed. São Paulo: Cortez, 2000.

Formação de professores: Identidade e saberes da docência. In: PIMENTA, Selma Garrido (Org.). Saberes pedagógicos e atividade docente. 4. ed. São Paulo: Cortez, 2005.

SAVIANI, Dermeval. Sistema Nacional de Educação e Plano Nacional de Educação. Significado, controvérsias e perspectivas. Campinas-SP: Autores Associados, 2014.

SHULMAN, Lee S. Conocimiento y enseñanza: fundamentos de la nueva reforma. Profesorado. Revista de currículum y formación del profesorado, vol. 9, n. 2, 2005, 30 p. Disponível em: 〈https://www.ugr.es/ recfpro/rev92ART1.pdf〉. Acesso em: 26 ago. 2013.

TARDIF, Maurice. Os professores enquanto sujeitos do conhecimento: subjetividade, prática, e saberes no magistério. In: CANDAU, Vera (Org.). Didática, currículo e saberes escolares. 2. ed. Rio de Janeiro: DP\&A, 2002, p. $112-128$.

Saberes, tempo e aprendizagem do trabalho no magistério. In: Saberes docentes $e$ formação profissional. 12. ed. Petrópolis (RJ): Vozes, 2011, p. 56-111.

TORRES, Rosa Maria. Tendências da formação docente nos anos 90. In: WARDE, Miriam Jorge (Org.). Novas políticas educacionais: críticas e perspectivas. São Paulo: PUC São Paulo, 1998. p. 173-191.

\section{SOBRE AS AUTORAS}

Roberta Miranda Silva é Mestre em Educação pela Universidade Federal de Uberlândia (UFU). E-mail: robertamiranda2112@gmail.com

Maria Célia Borges é Doutora em Educação pela Pontifícia Universidade Católica de São Paulo (PUCSP), com Pós-doutorado pela Faculdade de Educação da Universidade de São Paulo (FE-USP). É professora do Curso de Pedagogia e Licenciaturas no Instituto de Ciências Humanas do Pontal. É docente do Programa de Pós-graduação stricto sensu na Educação da Universidade Federal do Triângulo Mineiro (UFTM) e na Faced, Universidade Federal de Uberlândia (UFU).

E-mail: marcelbor@gmail.com; mariacelia@ufu.br 